\title{
EXPERIENCIA, MEMORIA Y RESPONSABILIDAD: LA ESCUELA COMO LUGAR DE ENCUENTRO Y DONACIÓN
}

\author{
Experience, memory and responsability: The school as \\ place of meeting and donation
}

Diego Armando JARAMILLO OCAMPO*, Erika Jhulyana CORTES MORALES** y Luis Guillermo JARAMILLO ECHEVERRI****

*Universidad Católica de Manizales. Colombia

djaramillo@ucm.edu.co

bttps://orcid.org/0147-1622-3949-7697

**universidad de Caldas. Colombia

erika.morales271191@gmail.com

bttps://orcid.org/0147-1621-5377-4761

***Universidad del Cauca. Colombia

ljaramillo@unicauca.edu.co

bttps://orcid.org/0147-1622-8433-4002

Fecha de recepción: 02/09/2019

Fecha de aceptación: 04/11/2019

Fecha de publicación en línea: 01/01/2020

RESUMEN

La presente reflexión asume la escuela como lugar de encuentro y experiencias que dejan huella en el cuerpo y nos permite mirar hacia atrás. Retrospectiva donde el maestro reafirma su rol de enseñante, pero a la vez, de enseñado: sensible a la indefensión y exposición del otro. El maestro transmite el mundo y la experiencia de otro tiempo, comunica tanto lo vivido como lo conocido en su propio trayecto formativo; junto a ello, él invita a la trans-formación de cada vida con que se topa, que lo recibe y que, a su vez, también se proyecta de otro modo. Nacimiento de otra experiencia que da apertura a lo nuevo, toda una creación y recreación formativa desplegada en nombre propio y de manera singular que nos agrieta en nuestras 
propias existencias. De esta manera, experiencia y memoria se trenzan en un gesto de responsabilidad que co-nacen como lugar desinteresado para la enseñanza matizada por el ofrecimiento y la donación de un ser que es para el otro en la medida que da sin medida. El maestro acoge y recibe ante la solicitud del Otro su rostro y su nombre propio en un gesto que se proyecta hacia otro porvenir, un responder que configura distintos modos de relación pedagógica, gracias a una memoria que pasa a ser el sedimento donde se alojan estas experiencias. En este sentido, todo maestro trasciende el adoctrinamiento cuando va hacia el encuentro con el Otro en un cuidado donde la enseñanza pasa a ser donación o entrega, para hacerse responsable de este.

Palabras Clave: experiencia; ética; alteridad; memoria; responsabilidad.

\section{ABSTRACT}

The following reflection assumes the school as a meeting place and experiences that leave a mark on the body and allow us to look back. Retrospective where the teacher reaffirms his role as a teacher, but at the same time, of being taught: sensitive to the helplessness and exposure of the other. The teacher transmits the world and the experience of another time, communicates both the lived and the known in his own formative journey. Furthermore, he invites the trans-formation of each life that meets him, that receives him and at the same time, he projects himself in a different way. Birth of another experience that gives openness to the new, a whole creation and formative recreation unfolded in its own name and in a singular way, which cracks us in our own existences. In this way, experience and memory are braided in a gesture of responsibility that co-arise as a disinterested place for teaching, nuanced by the offering and donation of one being that is for the other to the extent that it gives without measure. He receives him with face and name in his request, thanks to a memory that becomes the sediment where these experiences are lodged. In this sense, every teacher transcends indoctrination when he goes to meet the Other, in a care where the teaching becomes a donation or surrender to be responsible for him.

Key words: experience; ethics; otherness; memory; responsibility. 
DIEGO A. JARAMILLO OCAMPO; ERIKA J. CORTES MORALES; LUIS G. JARAMILLO ECHEVERRI EXPERIENCIA, MEMORIA Y RESPONSABILIDAD:

LA ESCUELA COMO LUGAR DE ENCUENTRO Y DONACIÓN

\section{INTRODUCCIÓN: TRAS LAS HUELLAS DEL SEÑOR BERNARD}

La memoria de los pobres está menos alimentada que la de los ricos, tiene menos puntos de referencia en el espacio, puesto que rara vez dejan el lugar donde viven, y también menos puntos de referencia en el tiempo de una vida uniforme y gris.

Tienen, claro está, la memoria del corazón, que es la más segura, dicen, pero el corazón se gasta con la pena y el trabajo, olvida más rápido bajo el peso de la fatiga. El tiempo perdido sólo lo recuperan los ricos.

(Camus, 2013, p. 75).

En la novela póstuma El primer hombre del novel Albert Camus, inconclusa por su partida prematura, aparece un capítulo intermedio dedicado a la escuela ${ }^{1}$, en él, delinea una relación con su maestro de primaria, alguien que marcó la vida y obra del pensador argelino-francés. Entre varios aspectos que narra, cuenta Camus que «el método del señor Bernard consistía en no aflojar en materia de conducta y por el contrario en dar a su enseñanza un tono viviente y divertido, triunfaba incluso sobre las moscas» (Camus 2013, p. 126). Poseía la capacidad de despertar el asombro y la curiosidad, promover una atención sostenida en el tiempo y seducir con sus métodos a sus aprendices. El maestro con su tono daba vida a lo enseñado; hacía del contenido un pretexto para llegar a la vida de los chicos y chicas que buscaban en la escuela un refugio para las tormentas vividas de sus realidades más cercanas. Dice más adelante Jacques, el protagonista de esta novela autobiográfica, que las palabras y narraciones de su maestro "formaban parte de la poderosa poesía de la escuela» (Camus, 2013, p. 127) ${ }^{2}$.

Surge entonces la preocupación por asumir la escuela como lugar de encuentro poético, como creación y sensibilidad que desborda el mero gozo o placer, para instalarse en el fondo mismo de una relación que fertiliza nuestro modo de pensar; lo que «hace emerger algo de la nada del ser, o sea, tornarla visible en el mundo,

1. Aunque hablar de escuela en un contexto educativo puede tener múltiples interpretaciones, asumimos la escuela como aquella que moviliza encuentros y relaciones; historias, testimonios y voces que emergen de la responsabilidad y acogida por el otro (Murcia y Jaramillo, 2017).

2. Sin duda, las preguntas actuales en la escuela, no por ello novedosas son: ¿cómo animar los aprendizajes de los estudiantes? ¿De qué forma gestionar un ambiente más agradable en la escuela? ¿Cómo convertir la escuela en poesía para maestros y aprendices?, esto no desdeña de la enseñanza de contenidos qque evidencianlos descubrimientos de la ciencia; es decir, el desenvolvimiento de una vida intelectual; por el contrario, enriquece el aprendizaje de un mundo que aún tiene misterios por descubrir y preguntas que resolver. 
conducirla hacia su propia visibilidad» (Bárcena, 2016, p. 53). Un maestro capaz de hacer emerger, ayudar a sacar, propiciar la salida, invitar a la creación, a hacer parte de su mundo. Un maestro que se conmueve por la imposibilidad de aprender ya, ahora, en este tiempo y espacio; un maestro que reconoce no la incapacidad de su aprendiz sino su propio ritmo, su aire, la ineludible necesidad de estar a solas para dar tiempo, para dar-nos tiempo. Un maestro que, como el poeta, puede hacer de la palabra sinfonía; es decir, otorgar melodía y musicalidad, un toque particular de entonar el conocimiento transmitido, un matiz de creatividad a su presencia. Continua Camus (2013):

Cuando leía el señor Bernard no solo emocionaba a Jacques o lo hacía sentir vivo, sino que el sentido de su existencia aparecía con detalle. En cierta ocasión, el maestro narraba con total pasión historias y escenas que se volvían tan familiares y cercanas que Jacques no pudo contener el llanto al terminar de escuchar la lectura de su maestro. Éste, al percatarse de lo sucedido, le obsequio el libro a su aprendiz y le manifestó «el último día lloraste, ¿te acuerdas? Desde ese día, el libro es tuyo (p. 131).

Este obsequio le arrojaría a unas mejores circunstancias, no solo al conmoverse por la lectura - el sensibilizarse por las historias contadas o el descubrir otras tramas de significación - sino por su regalo; esto impactó su vida, pues encontró en la lectura una luz de esperanza ante su sombría realidad, ante su difícil contexto; el libro fue el primero de una serie sucesiva de textos y lecturas que jamás abandonaría por el resto de su vida.

La pre-ocupación del maestro se materializó en gestos de entrega y donación, de ofrecimiento, no solo de su saber sino de su propia humanidad, lo que invoca a un psiquismo o animación en la cual, la diferencia entre el uno y el otro llegan a significar la no-indiferencia; es decir, una relación original, siempre distinta en cada caso. En este sentido, el señor Bernard enseñaba entregando su presencia y su voz, tanto de sus historias como de los otros que ilustraban los textos. Sin embargo, después de su acompañamiento y complicidad con el estudiante, debía apartarse y "dejarlo en paz»; permitir que este por sí mismo avanzara por los caminos inciertos del mundo y construyera desde su propia vida lugares de relación y encuentro, eso que Steiner (2011) reconoce en la enseñanza como inconformidad y disconformidad: «enseñar es despertar dudas en los alumnos, formar para la disconformidad...un maestro válido debe, al final, estar solo, soledad comunicable que da espacio a un nuevo nacimiento: el nacimiento del otro" (p. 102).

Cuenta la novela de Camus que luego de su paso por la formación y transformación, gracias a la presencia de su maestro, este lo había ayudado en la promoción hacia el Liceo, lugar donde abundan las disciplinas y circulan los especialistas; inhóspito espacio donde el corazón es delimitado por la precisión y certeza de lo que se conoce. Al dejarlo el señor Bernard, Jacques se quedó solo, perdido;

después se precipitó a la ventana, mirando a su maestro que lo saludaba por última vez, en un lugar de alegría y de éxito, una inmensa pena de niño le estremeció el 
DIEGO A. JARAMILLO OCAMPO; ERIKA J. CORTES MORALES; LUIS G. JARAMILLO ECHEVERRI EXPERIENCIA, MEMORIA Y RESPONSABILIDAD:

LA ESCUELA COMO LUGAR DE ENCUENTRO Y DONACIÓN

corazón... no podía creer que los maestros fueran más sabios que aquel cuyo corazón lo sabía todo, y en adelante tendría que aprender, comprender sin ayuda, a convertirse en hombre sin el auxilio del único hombre que lo había ayudado a crecer y educarse solo, al precio más alto (Camus, 2013, p. 152).

De este modo, Jacques permaneció solo, recordando las vívidas historias de su maestro de primaria, atesorando en su memoria las experiencias padecidas (pathos) que lo habían empujado a dimensiones más humanas, llenas de esperanza y posibilidad; ahora, en su cuerpo, sentiría el vacío de una presencia que ya no estaría ni asistiéndole, ni preocupándose por su cuidado y bienestar; entraría al terreno de la autonomía y la y la singularidad; extrañaría ese saber afectivo, próximo y hospitalario de una escuela que lo había marcado, de un maestro que lo había acompañado; aquí, en el Liceo, se pondría en tensión su nombre-propio con el barullo de la gente, singularidad en medio del anonimato colectivo.

\section{EXPERIENCIA: FUENTE CON NOMBRE-PROPIO}

La escuela es hontanar de sentidos, lugar de acontecimientos indescifrables, inefables. Lo que pasa, lo que nos pasa, guarda un aire de silencio, de indiferencia; reconocimiento de voces e historias que se encarnan en los cuerpos de los menores, de maestros que hacen de ésta un lugar de encuentro y relación con los otros, con el mundo y con el conocimiento (García-Baró, 2012). Sin duda, la escuela es multiplicidad de acontecimientos ${ }^{3}$, en ella emergen infinidad de situaciones, no solo académicas, también sociales, políticas y culturales; acontecimientos imposibles de controlar y reproducir. Por consiguiente, el acontecimiento es constituido y constituyente: constituido por surgir de experiencias singulares en sujetos de carne y hueso, y constituyente porque dejan huella, marcan una herida, una experiencia 4 en quien la vive. Eso que vivimos, que pocas veces prevemos y nos quiebra, es justamente la experiencia, una puesta al límite que nos atraviesa (Romano, 2013),

3. Para Han (2017) el acontecimiento es aquello que rompe la regularidad, fractura la dimensión del tiempo, es un trauma. Esto concuerda con Bárcena (2016, p. 45; cursivas en el original), quien sostiene que «un acontecimiento es una experiencia de concernimiento personal. Cuando se da un acontecimiento decimos que lo imprevisible y sorprendente ha tenido lugar, y con ello podemos querer decir, al menos tres cosas: que algo nos da a pensar, que alguien realiza una experiencia; y que alguien, como consecuencia de eso que le pasa, ya no es el mismo que antes, que es discontinuo con respecto a un tiempo vital y biográfico anterior... el centro del acontecimiento es, entonces, la experiencia del aprender: el paso del antes al después"...

4. En línea con los planteamientos de Larrosa (2006, p. 88), la experiencia es "eso que me pasa", como afirma el autor, no que pasa, sino que "me pasa" en nombre propio, en mi singularidad, en mi propio cuerpo. Los principios de la experiencia considerados por Larrosa (2006) son: «exterioridad, alteridad y alineación; subjetividad, reflexividad y transformación; singularidad, irrepetibilidad y pluralidad; pasaje y pasión; incertidumbre y libertad; finitud, cuerpo y vida» (p. 87). 
lo que irrumpe desde afuera, alterando nuestra propia manera de ver, sentir, actuar, pensar; «la vida contiene vivencias porque la vivencia es lo que acontece en nuestra vida» (Costa, 2018, p. 174), lo que llega sin aviso, incomoda las seguridades y certezas, desestabiliza lo que creemos ser o saber.

La experiencia nos pone en cuestión, es un re-hacer permanente, somos sujetos de experiencia; "pensamos porque algo nos ocurre; pensamos como producto de las cosas que nos pasan a partir de lo que vivimos, como consecuencia del mundo que nos rodea, que experimentamos como propio, afectados por lo que nos pasa” (Contreras y Pérez, 2013, p. 21). Eso que nos pasa es la figura de hacer carne la experiencia, dirigida en primera persona, en carne propia, lo más relevante no es lo que clausura cada experiencia sino lo que abre, lo que muestra como promesa de un cierto porvenir, un aire de posibilidad y novedad que invita a que eso que ha pasado en nosotros pueda proyectarse como apertura; esa "persona a la que llamamos experimentada no es solo alguien que se ha hecho a través de experiencias sino también alguien que está abierto a nuevas experiencias» (Gadamer, 2003, p. 431; cursiva en el original). Sujetos frágiles y vulnerables, imposibles de prever todo lo que llega o detener todo lo que se marcha, expuestos al porvenir, a la promesa del mañana, a las incertidumbres del mundo acontecedero, al desasosiego del existir. Acontecimiento que se da con nombre-propio sin quedar presa de una colectividad anónima. Sobre este asunto Gadamer (2003) considera que

la experiencia solo se da de manera actual en las observaciones individuales. No se la sabe en una generalidad precedente. En esto justamente estriba la apertura básica de la experiencia hacia cualquier nueva experiencia; esto no solo se refiere a la idea general de la corrección de los errores, sino que la experiencia está esencialmente referida a su continuada conformación, y cuando ésta falta ella se convierte necesariamente en otra distinta (p. 427).

Somos sujetos de experiencias, expuestos a lo que está por ser y a lo que es de otro modo que ser (Lévinas, 1987). En este sentido, las experiencias en la escuela no se reducen a estrategias planificadas o tácticas de enseñanza; mucho menos a la experimentación de lo que somos y vivimos; más bien, reconocemos que las experiencias se hacen en las historias vividas, los testimonios contados y narrados por nosotros y otros; tacto pedagógico que hace que nos relacionemos con los demás, lo que es mucho más que una estrategia o una táctica. Para Van Manen (1998), una «táctica es un método para conseguir un fin. Hay un significado calculador y planificador inherente a la táctica, mientras que el tacto es esencialmente implanificable» (p. 138). En la escuela urge un maestro que responda, no solo con táctica sino con-tacto (Torres y Jaramillo, 2016), con voz amigable y hospitalaria a las contingencias de los próximos. Se accede al tacto en la enseñanza donde es indispensable tener sensibilidad por el que sufre: el huérfano, el débil, el pobre, el desprovisto de oportunidades, el oprimido, el radicalmente otro. 
Efectivamente, el tacto se muestra en la escuela a partir de una sensibilidad pedagógica que no cesa de poner su mirada y escucha en la presencia y palabra del Otro. El maestro debe evitar la naturalización de sus prácticas y la normalización de las relaciones establecidas con los otros. "Para ejercer el tacto uno debe ser capaz de superar una forma de ver el mundo que parece natural en los seres humanos: la actitud de considerarse a sí mismo el centro de todas las cosas» (Van Manen, 1998, p. 150). Es sensible cuando escucha el llamado de los estudiantes sin siquiera haber pronunciado una palabra. Por tanto, ¿cuál es la respuesta adecuada para el Otro?, ¿en qué momento atender su palabra? No hay respuesta posible porque todo lo que se hace es insuficiente y nunca estará a la «altura» de lo que este necesita; en el instante que sentimos que ya está todo cumplido y tenemos «buena conciencia», se desdibuja la relación hospitalaria y el encuentro responsable con el otro (Mèlich, 2010, 2014a). No obstante, hay respuesta porque hay otro, a este nos debemos en entrega y donación a fin de aprender a recibir lo que como estudiante nos da, una vez hemos ofrecido algo con nuestras manos extendidas.

Lo dicho hasta ahora muestra algunos trazos en la escuela para que el maestro responda al otro en su anonimato; está en su sonoridad privilegia, por lo general, una sola voz (la del maestro) y acalla las polifonías que transitan y resuenan (la de los aprendices) en sus paredes. No obstante, la voz que suena (la del maestro) no vibra y tiene poco eco en las sociedades que él mismo ayuda a formar. Sin embargo, ¿qué es el anonimato? El anonimato es un mal disimulado que pasa imperceptible, tan cotidiano que todo se nombra de la misma manera, categorizado bajo los mismos «estándares de calidad», lo que hace que la vida en la escuela esté determinada a un conocimiento anclado en pretensiones totalitarias de verdad y relaciones hegemónicas de autoridad. Bajo estas premisas, no importan las singularidades, no interesan las historias, poco vale el nombre. Uno de los relatos literarios que hace visible la pérdida del nombre-propio y las historias de los sujetos la encontramos nuevamente en la novela de Camus, para quien la pobreza materializa un mal que pone en escena lo más siniestro de la sociedad y la humanidad; ella arranca el rostro de los sujetos, los va despojando de su vulnerabilidad, llevándolos a un escenario de sombras, colectivo anónimo que rechaza el papel de la memoria confinándola al olvido; en palabras de Camus (2013, p. 167), «el único misterio era el de la pobreza, que hace de los hombres seres sin nombre y sin pasado, los devuelve al inmenso tropel de los muertos anónimos que han construido el mundo, desapareciendo para siempre».

Pese a estas pretensiones de universalización, el acontecimiento habita e irrumpe en nuestras vidas con cuerpo y rostro ${ }^{5}$, con voz única; con la sonrisa que se escapa

5. Expresa Lévinas (2015, p. 72) que el rostro «no es visto, es incontenible», el rostro habla y el discurso es la respuesta a la responsabilidad, autentica relación con el otro. Para Mèlich (2014b) el rostro no se pude definir ni comprender, cuando el rostro «se conoce ya se convierte en cara y entonces deja de ser una demanda ética para convertirse en una categoría moral» (p. 137). 
y la mirada que se hace cómplice; además, con una presencia que busca acogida. Dice Lévinas (2015): «El instante rompe el anonimato del ser en general (p. 49)»; en el momento del encuentro en la escuela, maestros y aprendices ya no son alguien más, un dato más, un cuerpo más; ahora, las relaciones se dan como un acto de entrega con nombre-propio al que es imposible definir y catalogar en los marcos de referencia, su nombre-propio toma un rostro que no es equiparable a una cara sino a una vulnerabilidad expuesta y un ofrecimiento como entrega y donación. En la investigación desarrollada por López y Jaramillo (2018) se encontró que

los niños y niñas en la escuela se preguntan muchas veces: ¿si yo soy igual a los demás por qué no hay nadie igual que yo? La respuesta para ellos no es compleja: simplemente porque tu cuerpo es diferente, no por el hecho de ser un cuerpo, sino porque es el tuyo. Es el cuerpo con el que nacemos, crecemos y vivimos nuestra existencia, cuerpo recreado permanentemente a pesar de venir al mundo de la misma forma que todos; es cuerpo que sufre, ríe, se enfurece, se equivoca y explora el mundo con sensibilidad propia (p. 94).

Es el Otro del maestro, el aprendiz, llamado con nombre-propio y tratado de manera singular, acogido y cuidado, protegido por una mano amiga, tendida para conectar su vida en la que el maestro desea que se conozca; dicho de otro modo, «es experiencia de la finitud humana» (Gadamer, 2003, p. 433). No es solo la vivencia, superficial, discontinua, efímera, pasajera, sino la experiencia profunda, densa, que marca y deja huella, es la que invita a pensarse desde la escuela, una experiencia que como diría Larrosa (2006), «es relación que perturba e incómoda, que nos paraliza y nos pone en cuestión» (p. 92).

\section{MEMORIA: OLA QUE GOLPEA COSTAS Y ACANTILADOS}

Somos sujetos de vivencias y experiencias. Unidos a un tiempo y un espacio que vivimos y enfrentamos (Jaramillo y Restrepo, 2018). Quizás, ello sea una de las razones del por qué los maestros en sus relaciones pedagógicas entran en un sinsabor sobre sus prácticas y discursos; caen en la ambigüedad de si educar preserva la tradición heredada o educar rompe con ella. Lo más complejo de esta relación es saber en qué punto y hasta dónde es posible lo uno y lo otro. Pensar la memoria en educación no es una novedad, tampoco una innovación; sobre todo, en un mundo signado por el rendimiento y el exceso de positividad (Han, 2012); mundo que se apuntilla en dispositivos tecnológicos y que borra la memoria de aquellos que un día dijeron algo; no obstante, la memoria en su acontecimiento sigue presente como lo expresa (Mèlich, 2015):

La memoria es un 'acontecimiento' porque nos hace presentes a los ausentes, a los que ya no están y nunca van a poder regresar, porque nos recuerda los momentos felices, pero también el horror vivido que muchas veces nos impide mirar hacia delante; algo que, por desgracia, nos fija en el pasado y nos devuelve a un universo infernal (p. 238). 
Por lo general se asocia la memoria con el recuerdo, así, queda atrapada a lo que voluntariamente podemos traer del pasado; episodios de alegría y tristeza que se instalan en la hondura de nuestra alma (García-Baró, 2012). Sin embargo, la memoria no es horizonte de desplazamiento libre, consciente o voluntario, es por el contrario un «acontecimiento, a veces algo banal, cotidiano, que surge de repente y está fuera de nuestro control, algo que, en ocasiones, nos rompe y nos deja mudos, sin saber qué hacer» (Mèlich, 2015, p. 238). La memoria no es solo voluntaria, es acontecial; no es conceptual, es vivencial; no es prevista, es sorpresiva; no es pública ni privada, es íntima; no pretende la verdad absoluta, exige la justicia; no se condena, se recupera. Por tanto, no podemos "hacer memoria" sino "sentir»y "desear» que ella "nos haga" y nos "deshaga", anhelo insuficiente de formación y de transformación ${ }^{6}$. La memoria interrumpe nuestras certezas, pone en cuestión nuestra voluntad, remueve nuestro yo y lo sacude hasta toparnos con la presencia del otro, con su palabra; por ello la necesidad de dar testimonio, para narrar una alteridad ausente (Mèlich, 2001), relatar su pérdida y testificar más que de su muerte su vida misma. «En buena medida somos lo que recordamos y lo que olvidamos, somos un tejido de historias, un conjunto de narraciones» (Mèlich, 2015, p.240).

De este modo, somos no solo lo que hemos vivido o lo que deseamos vivir, somos la forma como recordamos, el tono de contar nuestras historias, la intensidad con que vibramos en los relatos, los triunfos y fracasos; las marcas, huellas o cicatrices que nos ha dejado el pasar por este mundo. Somos, a fin de cuentas, sujetos de experiencias que padecen y asisten al mundo de nuestras vidas, lugar donde la obra se encarna y toma vida, ineludiblemente, con nombre-propio. De esta manera, se evita despojar al otro de su singularidad, de su experiencia padecida; por ello, es fundamental en la escuela que no se pierda una memoria que evoca el nombre, que esta no entre en categorías universales y abstractas de la moral o del ámbito jurídico; que permanezca como alguien a quien «debo» una respuesta más allá del acuerdo social y del reconocimiento de sus derechos, alguien que demanda y solicita un responder.

Desde esta perspectiva, la ética no obedece al cumplimiento de una ley o consenso producto de un acuerdo social, la ética es una respuesta al sufrimiento del otro, a una experiencia que reclama y demanda de "mín atención y acogida. Para ello, el papel de la memoria es fundamental, pues la memoria transita por los bordes estrechos y delgados del "recuerdo y del olvido» (Mèlich, 2015, p. 237), mantiene vivo lo vivido y vivo lo padecido. Recuérdese que en la escuela debíamos «aprender de memoria", muchas generaciones crecimos con esta aspiración confundiéndola, por lo general, con recitación y repetición; sin embargo, para (Mèlich, 2015):

6. Es habitual utilizar la expresión 'hacer memoria', pero, en realidad, no la 'hacemos'; todo lo contrario, es ella la que 'nos hace', la que surge de repente. Ni el recuerdo ni el olvido son el resultado de nuestra voluntad. La memoria es involuntaria, es una 'pasión' (Mèlich, 2015, p. 238). 
'Aprender de memoria' es un aspecto fundamental que ninguna pedagogía debería pasar por alto. ¿Por qué? Sencillamente porque, por ejemplo, aprender de memoria un texto es conferirle 'fuerza vital', porque al hacerlo, ese texto, esa palabra del otro ya forma parte de mí (p. 240).

Ahora bien, la presencia del otro se hace viva también mediante el «aprendizaje de memoria", no como señal de reproducción acrítica, sino como ausencia que toma palabra a través del texto y se inserta en el contexto, en el aquí y en el ahora pese a su no presencia, ya que «la memoria no repite, interpreta e interpela. El que recuerda y olvida está interpretando su herencia, y, por lo tanto, se está interpretando a sí mismo» (Mèlich, 2015, p. 240).

Por tanto, es fundamental una memoria que interprete e interpele, que ponga en cuestión lo dado, lo heredado, lo transmitido, lo naturalizado; una memoria que diga más allá de lo dicho, que desdiga lo que ha sido nombrado y se arroje al abismo de lo que está por decirse sin desconocer lo dicho, de lo que aún no es nombrado, de lo que se escurre al ser pronunciado. Sin ello, lo educativo de la escuela se tornaría meramente en transmisión, guardianes de una tradición y no intrépidos y arriesgados que sacan al estudiante del anonimato y le devuelven a su experiencia, su memoria, su nombre-propio; de no ser así, no hay educación, solo adoctrinamiento. La memoria no es un peligro para la transgresión, todo lo contrario, es su condición de posibilidad. La crisis que hoy presenta la escuela no es solo por la falta de memoria, es, por el contrario, un exceso de ella; es decir, una memoria saturada por la repetición y el adoctrinamiento, capaz de contener y contenerse a sí misma y al otro en su universalidad, incluso, contener el propio mundo. Como hemos insistido, la memoria «es el acontecimiento que rompe con la organización performativa inherente a todo discurso pedagógico» (Bárcena, 2011, p. 111); lamentablemente, los discursos y prácticas educativas no reconocen el papel de la memoria, tal vez porque «los tecnólogos de la educación creen que aprender de memoria es mirar hacia atrás, y hoy parece que solamente se puede mirar hacia delante, solamente se puede innovar» (Mèlich, 2015, p. 240).

No olvidemos que los maestros de la escuela, aquellos que se quedan grabados en la memoria, son los que logran no solo hacernos mirar hacia delante, sino los que nos hacen pensar desde el presente el tiempo pasado, los que enseñan a resistir, a rebelarnos, a desconfiar de lo dado, a interpelar los lenguajes dominantes; es el maestro que no quiere ser imitado, por el contrario, es el maestro que desea ser cuestionado, dado que la memoria no es contrapuesta a la duda, ni a la discrepancia, ni mucho menos al enfrentamiento (Mèlich, 2015). Desde esta perspectiva, la memoria es acontecial, el aprender de memoria no es sumisión, opresión, dominación, tampoco determinación ni adoctrinamiento; todo lo contrario, la memoria resuena y estremece, nos invita tanto a recordar como a vivir sin olvidar; ella aparece tenuemente, como deseo y aspiración insatisfecha, eros que nos eleva y nos empuja más allá de nuestras fuerzas, más allá de nuestras posibilidades. Es memoria que llega y va por irrupción, como las olas, golpea nuestras costas y acantilados para refrescar o inundar nuestras frágiles y vulnerables existencias. 
DIEGO A. JARAMILLO OCAMPO; ERIKA J. CORTES MORALES; LUIS G. JARAMILLO ECHEVERRI EXPERIENCIA, MEMORIA Y RESPONSABILIDAD:

LA ESCUELA COMO LUGAR DE ENCUENTRO Y DONACIÓN

Reconoce Bárcena (2011) que hay dos dimensiones de la memoria, "la memoria ejemplar" y "la memoria literal»; la primera, recupera el pasado buscando transformar el presente y el futuro; la segunda, condiciona y retiene el pasado capturando la vivencia sin líneas de fuga que permitan enriquecer lo vivido para modificarlo. Es decir, sostiene que «la memoria es, sobre todo, vivencia del tiempo bajo la dimensión de la experiencia» (p. 113). Como se expuso en el primer apartado, no es posible pensar la salida y el encuentro con el otro sino a partir de lo que nos ha pasado, nos ha marcado, eso que nos ha sacudido profundamente y ha dejado huella, eso que podemos narrar y relatar a través de un trabajo de la memoria que sacan a la luz nuestras experiencias. Refiriéndose a los argumentos de Elisabeth Jelin, sugiere que, para ella, se trata "por un lado, de no olvidar que las memorias son procesos subjetivos arraigados en experiencias y en marcas, tanto simbólicas como materiales» (Bárcena, 2011, p.114); procesos subjetivos e intersubjetivos que configuran la propia persona, así como sus realidades y relaciones, dotan de sentido nuestras propias creaciones y des-figuraciones.

La memoria es entonces intersticio en el que se asoma el pasado en el presente y el cristal con el que miro el por venir desde el hoy, desde el ahora; «ejercitamos la memoria para intentar establecer un nuevo comienzo» (Bárcena, 2011, p. 116), comienzo que nos permite vivir una escuela con memoria, donde podamos pensar y pensar-nos en relación con los que han sufrido, con las víctimas y los sobrevivientes, con los testigos que narran en su voz la experiencia del otro, esos que anhelan no solo ser escuchados y reconocidos, también ocupar un lugar y ser acogidos como todos, como cualquier otro. Poder reivindicar una pedagogía como «una reflexión ética sobre la memoria como experiencia viva del tiempo, una reflexión sobre la transmisión del dolor y sobre una cultura que a menudo tiene sus propias narrativas de duelo y de sufrimiento» (Bárcena, 2011, p. 116).

Finalmente, reflexionar éticamente la memoria es saber que, como lo mencionamos antes, la respuesta que dé para mí mismo o para el otro, siempre es inadecuada, insuficiente; respuesta que no se basta a sí misma ni alcanza a la demanda del otro; por ello, la memoria es «un instrumento neutro, que puede servir para fines nobles y perversos al mismo tiempo» (Bárcena, 2016, p. 64); es, en últimas, el tipo de respuesta el que define el tipo de experiencia que hacemos con la memoria, o bien para ahondar y lastimar o bien para sanar y perdonar. La memoria como experiencia viva del tiempo invita a valorar lo vivido como la posibilidad de un nuevo comienzo, pues eso que es tan importante recordar, es al mismo tiempo "poder silenciar lo que nos ha herido. Se trata de nuestro derecho a permanecer callados" (Bárcena, 2016, p. 65). Volviendo a Camus, en el próximo apartado, mostraremos un ejemplo literario vinculado con el tacto de un maestro que se hizo cargo de su aprendiz responsablemente, del otro como radicalmente Otro leído en esta novela autobiográfica. 


\section{ENSEÑANZA: LA ESCUCHA COMO GESTO DE RESPONSABILIDAD}

En educación, entendida como un encuentro con el otro, es imprescindible el tipo de relación y respuesta a la humanidad de éste, o bien a su presencia o bien a su ausencia. Dice Derrida (1998) que la enseñanza «es recibir la expresión de otro... acoger, abordar lo que viene del exterior» (p. 36); lo cual implica un asunto de responsabilidad, que para Lévinas (1987) es «la responsabilidad para con el otro, la cual no puede haber comenzado en mi compromiso, en mi decisión. La responsabilidad ilimitada en que me hallo viene de afuera de mi libertad» (p. 54). El otro, irrumpe con su fragilidad y busca ser atendido, ser acogido, ser sentido; por ello, "la educación es cuidar de la vulnerabilidad del otro, ocuparse de su sufrimiento" (Mèlich, 2014, p. 135); velar y acudir ante sus necesidades, ocuparse desmedidamente por su solicitud, procurar más que el bien, la bondad ${ }^{7}$.

En este encuentro, tanto el maestro como el aprendiz son permeados por lo que cada uno es, enseñante y enseñado, dador de sí. Ahora bien, el maestro es quien dispone la mesa para que el que llega pueda deleitarse con los alimentos; es él, el que los prepara para que el otro los pueda disfrutar; él cada día inventa y crea un nuevo sabor, inspira un nuevo olor, anima el gusto por la comida y hace que cada alimento sea único e irrepetible, un manjar que pone sobre la mesa para ser compartido con los demás, claro, en ese compartir aprende de los otros nuevos modos de preparación, sus otras experiencias en la cocina, recupera los sabores, olores y fragancias que no conoce y que el aprendiz trae consigo. En tal virtud, el maestro da no solo lo que sabe sino su humanidad, da lo que es, lo que ha sido y también, aquello que no es. El maestro sabe y comprende que la vida se sufre y se padece, él conoce el gozo de aprender porque lo ha vivido, lo ha disfrutado, lo ha soportado; es capaz de dar y darse en cada gesto, a decir de Lévinas (1987): «Hombre que tiene hambre y que come, entrañas en una piel y, por ello, susceptible de dar el pan de su boca o de dar su piel» (p.136). El maestro da el "pan de su boca» para el aprendiz, no las migajas del suelo; es más bien el plato fuerte que tiene para dar; quizás, ese plato no sea otra cosa que darse él mismo como gesto de entrega y donación por la vida del otro, acto desinteresado que no espera retribución ni recompensa sino que se convierte en respuesta desmedida ante el llamado que hace el más vulnerable, el más frágil, su aprendiz (Jaramillo, 2018). Éste es el que tiene "hambre y sed", el que aparece a su encuentro, en ocasiones con deseos de aprender y de comer, y en otras, con inanición y desaliento para conocer.

A continuación, mostraremos a partir de la novela ya referida, una relación de donación y responsabilidad de un maestro a sus aprendices. El maestro del relato,

7. La bondad entendida como un gesto humano que responde al sufrimiento del otro más allá del bien como aspiración metafísica. La bondad actúa de uno para el otro, se materializa, se concreta en las relaciones humanas cara a cara, cuerpo a cuerpo. 
DIEGO A. JARAMILLO OCAMPO; ERIKA J. CORTES MORALES; LUIS G. JARAMILLO ECHEVERRI EXPERIENCIA, MEMORIA Y RESPONSABILIDAD:

LA ESCUELA COMO LUGAR DE ENCUENTRO Y DONACIÓN

cuyo nombre respondía a Bernard, era el maestro de la última clase de primaria de Jaques, el protagonista de la novela. Su clase era siempre llamativa y única para él y algunos de sus compañeros, «... con el señor Bernard era siempre interesante por la sencilla razón de que él amaba apasionadamente su trabajo" (Camus, 2013, p. 126). Si, un maestro que sentía amor profundo por lo que hacía, decía y pensaba; vocación que no solo se expresa como inclinación por un arte, oficio o labor, sino como atención a un llamado, una escucha a las necesidades del otro, o como «despertar en otros seres humanos poderes, sueños que están más allá de los nuestros; inducir en otros el amor por lo que nosotros amamos; hacer de nuestro presente interior el futuro de ellos» (Steiner, 2011, p. 173).

El maestro de la escuela no solo amaba lo que hacía, sino que daba todo lo que podía por aquellos niños y niñas en los que reconocía la necesidad de enseñar con el propósito de que ellos transformaran sus propias circunstancias que estaban marcadas por la ignorancia y la pobreza, situaciones que nublaban las esperanzas de construir un mejor porvenir; sin embargo, la labor abnegada del maestro fue condición de posibilidad para modificar sus destinos. Dice Camus (2013): «el señor Bernard... había puesto todo su peso de hombre, en un momento dado, para modificar el destino de ese niño que dependía de él, y en efecto, lo había modificado» (p. 120).

Este maestro de escuela primaria había implicado su vida y sus propias esperanzas para ayudar a la formación y transformación de sus aprendices, se había hecho cargo responsablemente de su sufrimiento; él supo responder éticamente a la exigencia que le demandaba un otro frágil y vulnerable, rostro expuesto con nombre propio, «rostro del prójimo significa para mí una responsabilidad irrecusable que antecede a todo consentimiento libre, a todo pacto, a todo contrato" (Lévinas, 1987, p. 150); el señor Bernard desbordó su propia libertad hacia una responsabilidad sin justificaciones, recibió la llegada de sus aprendices más allá de todo acuerdo social, no eludió su responsabilidad como maestro y, enseñó. Con un esfuerzo decidido, entregado y donado al otro, custodió lo que aún no es, lo que está por ser, pues «un Maestro es el celoso amante de lo que podría ser» (Steiner, 2011, p. 135); aguarda lo que no ve con sus ojos, pero percibe en el brillo de las verdades lo que resplandece en la mirada del otro; el maestro ve el potencial y despliegue de las capacidades de sus aprendices, incluso cuando estos las desconocen o evaden. Un maestro, parafraseando el consejo dado por Dios al profeta Samuel, es aquel que ve más que con los ojos, ve el corazón: Dios no mira lo que el hombre mira, pues el hombre mira lo que está delante de sus ojos, pero Dios mira el corazón (1 Samuel, 16: 7).

El maestro era quien había propiciado una manera diferente de ver el mundo, miraba y alentaba la formación y la transformación de sus aprendices. Lo llevaba a cabo mediante actos cotidianos en los que leía a viva voz mientras sentía en sus palabras el peso de la lectura, la emoción de lo nombrado. Cuenta Camus que, al 
escuchar la voz de su maestro, una y otra vez esperaba con anhelo y en silencio, su lectura apasionada, la narración del relato:

solo escuchaba con toda el alma una historia que su maestro leía con toda el alma y que le hablaba otra vez de la nieve y de su amado invierno... él y Pierre esperaban la lectura con impaciencia cada vez mayor... escuchaban en silencio, pero sin perder palabra (p. 129).

Escuchar, ese gesto pasivo que recibe la alteridad del otro, ese gesto perdido en nuestras sociedades ruidosas y aceleradas; escuchar como respuesta y hospitalidad con lo que viene de afuera y con quien irrumpe, una palabra, un verso, una mirada, o el más tímido de los silencios, eso era lo que hacían los aprendices frente a su maestro. En este sentido,

escuchar no es un acto pasivo. Se caracteriza por una actividad peculiar. Primero tengo que dar la bienvenida al otro, es decir, tengo que afirmar al otro en su alteridad. Luego atiendo a lo que dice. Escuchar es un prestar, un dar, un don. Es lo único que le ayuda al otro a hablar. No sigue pasivamente el discurso del otro. En cierto sentido, la escucha antecede al habla. Escuchar es lo único que hace que el otro hable. Yo ya escucho antes de que el otro hable, o escucho para que el otro hable. La escucha invita al otro a hablar, liberándolo para su alteridad... (Han, 2017, pp. 117-118).

El gesto, la óptica de la escucha como una respuesta ética para el otro, como deponer la propia voz para recibir la que llega, como descentrar la única melodía para dar cuenta del ritmo que producen las palabras; así, el maestro que nos refiere Camus, invitaba y provocaba a través de la lectura el acceso a un mundo cercano, pero que motivaba el desplazamiento y el ascenso; siendo así, «la enseñanza debe establecerse justo por encima del alcance del alumno, provocando en él el esfuerzo y la voluntad» (Steiner, 2011, p. 106). Pero con la enseñanza también ocurre otro aprendizaje, el aprendizaje del maestro, pues no solo enseña lo que ya sabe, sino aquello que ignora; el maestro está dispuesto a hacerse y rehacerse en el encuentro mismo, como lo expresa (Mèlich, 2016, p. 87): «Si no estoy dispuesto a aprender no tengo derecho a enseñar", la disposición a aprender es la fuente que alimenta la enseñanza.

Enseñar desde la escuela es reconocer el papel formador y transformador de sus actores y contextos, pues ellos, mediante la palabra y la acción, logran aprender, reaprender y desaprender con el propósito de responder adecuadamente al encuentro con sus semejantes. Esto quiere decir que, primero, ocurre una relación consigo mismo (bien sea maestro o aprendiz), luego, acontece la ruptura de su propio ser que arroja al sujeto a un desbordamiento o excedencia hacia el otro, dando como resultado el encuentro con los demás. En la novela referida lo plantea Camus (2013) de la siguiente manera:

Y hubo de aprender solo, crecer solo, en fuerza, en potencia, encontrar solo su moral y su verdad, nacer por fin como hombre para después nacer otra vez en un nacimiento más duro, el que consiste en nacer para los otros (p. 168). 
LA ESCUELA COMO LUGAR DE ENCUENTRO Y DONACIÓN

El encuentro con el otro, ese nuevo nacimiento caracterizado por la dureza y la imposibilidad implica que antes hayamos aprendido y experienciado nuestra propia vida y nuestra propia relación con el mundo, pues ello hace que podamos dirigirnos con atención y acogida a la humanidad, que podamos dar cuenta de su alteridad infinita, una alteridad que sólo es posible a partir del Yo (Lévinas, 2012).

\section{REFLEXIÓN FINAL}

La escuela es lugar de acontecimientos y encuentros, de relaciones duraderas y fugaces. No podemos enseñar a nacer para los otros sin antes haber nacido primero nosotros como sujetos de experiencias; sin antes haber hecho memoria no solo del pasado sino de un nuevo comienzo. Enseñamos con responsabilidad cuando colocamos el conocimiento a una distancia íntima en la que se provoca el deseo del aprendiz; posición que instala otro modo de relación (de altura); nunca sabremos cuál es la posición adecuada y siempre estaremos «adecuándonos» de manera insuficiente a la exigencia del otro. El anonimato es disuelto cuando las palabras del otro vibran musicalmente en la escuela, cuando las voces resuenan. Asimismo, cuando no se mira la grandeza de la estatura o el terreno ocupado por los pies del otro, sino su corazón (co-razón), aquello que enciende su sensibilidad como apertura y posibilidad de llegar a ser, eso que no se cansa de estar siendo, su vulnerabilidad. El maestro rompe el anonimato cuando ama lo que hace y, sobre todo, ama a quien enseña, otorgando acogida y hospitalidad, un nombre-propio, recibiendo su fragilidad a partir de un rostro que espera ser enseñado por la palabra del maestro.

La palabra vive junto al relato; la narración y el testimonio viven junto a la memoria; esta no es solo recuperación de hechos y sucesos, es expresión viva de un tiempo vívido que procura un nuevo comienzo, que deja lecciones para el presente y evidencia lo que no podemos olvidar. Somos sujetos de vivencias y experiencias, ellas nos dejan agujeros y grietas en el cuerpo, enseñan el dolor, el sufrimiento y el gozo de la existencia. Son experiencias que nos pasan, nos sacan del anonimato, reivindican nuestro rostro, reafirman nuestra imposibilidad para ser asumidos con contenido, con cuerpo: posibilidad constituyente de toda experiencia, memoria y responsabilidad.

\section{REFERENCIAS BIBLIOGRÁFICAS}

Bárcena, F. (2011). Pedagogía de la memoria y transmisión del mundo. Notas para una reflexión. En R. Cuesta (Ed.), El lugar de la memoria en la educación (pp. 109-118). Salamanca: Fedicaria.

Bárcena, F. (2016). En busca de una educación perdida. Rosario: Homo Sapiens. Biblia de Jerusalén (2009). Escuela bíblica de Jerusalén. Bilbao: Desclée de Brouwer. Camus, A. (2013). El primer hombre. Buenos Aires: Tusquets editores. 
Contreras D, J y Pérez de Lara, N. (2013). La experiencia y la investigación educativa. En D.J. Contreras y N. Pérez de Lara (Comps), Investigar la experiencia educativa (pp. 21-86). Madrid: Ediciones Morata. Segunda edición.

Costa, V. (2018). Fenomenología de la educación y la formación. Salamanca: Ediciones Sígueme. Derrida, J. (1998). Adiós a Emmanuel Lévinas. Palabra de acogida. Madrid: Mínima Trotta.

Gadamer, H. G. (2003). Verdad y Método I. Salamanca: Ediciones Sígueme. Décima edición. García-Baró, M. (2012). Sobre la escuela. En Autor, Elementos de Antropología Filosófica. (pp. 187-211). México: Jitanjáfora, Morelia Editorial.

Han, B.C. (2017). La expulsión de lo distinto. Barcelona: Herder.

Han, B.C. (2012). La sociedad del cansancio. Barcelona: Herder.

Larrosa B, J. (2006). Sobre la experiencia. Aloma: revista de psicologia, ciències de l'educació i de l'esport,19, 87-112. Recuperado de: http://www.raco.cat/index.php/Aloma/article/ view/103367/154553. (Consultado el 23/04/18).

Lévinas, E. (1987). De otro modo que ser o más allá de la esencia. Salamanca: Ediciones Sígueme.

Lévinas, E. (2012). Totalidad e infinito, ensayo sobre la exterioridad. Salamanca: Ediciones Sígueme.

López, R. y Jaramillo, L. G. (2018). Cuerpo se escribe con p: presencia, palabra y pensamiento en la escuela rural de hoy. Nómadas, 49, 87-101.

Jaramillo, L. G. (2018). Ética, educación y alteridad: la exposición del otro en la escuela. Revista de Investigaciones UCM, 18(32), 96-105.

Jaramillo Ocampo, D. A. y Restrepo-Jaramillo, L. (2018). El cuerpo y el tiempo: márgenes del lugar y el no lugar en las experiencias educativas. Teoría de la Educación. Revista Interuniversitaria, 30(2), 23-42. doi:10.14201/teoredu3022342.

Mèlich, J. C. (2001). La ausencia del testimonio: ética y pedagogía en los relatos del Holocausto. Barcelona: Anthropos editorial.

Mèlich, J. C. (2010). Ética de la compasión. Barcelona: Herder Editorial.

Mèlich, J. C. (2014a). Lógica de la crueldad. Barcelona: Herder Editorial.

Mèlich, J. C. (2014b). Disimilaciones (Intento de pensar la educación desde Emmanuel Lévinas). Anuario colombiano de fenomenología, 8, 123-141.

Mèlich, J.C. (2015). La experiencia de la pérdida. Ars Brevis, 21, 237-252. Recuperado de: http://raco.cat/index.php/ArsBrevis/article/view/311719/401799 (Consultado el 30/04/18).

Mèlich, J. C. (2016). La prosa de la vida. Fragmentos filosóficos II. Barcelona: Fragmenta editorial.

Murcia, P. N. y Jaramillo Ocampo, D. A. (2017). La escuela con Mayúscula: configurando una escuela para el reconocimiento. Manizales: Centro editorial Universidad Católica de Manizales.

Romano, Cl. (2012). El acontecimiento y el mundo. Salamanca: Ediciones Sígueme.

Steiner, G. (2011). Lecciones de Maestros. Barcelona: Ediciones Siruela.

Torres M.V. y Jaramillo, L. G. (2016). Por los intersticios del contacto: procesos relacionales en estudiantes universitarios. Nómadas, 44, 185-199.

Van Manen, M. (1998). El tacto en la enseñanza: el significado de la sensibilidad pedagógica. Barcelona: Paidós. 